This item was submitted to Loughborough's Research Repository by the author.

Items in Figshare are protected by copyright, with all rights reserved, unless otherwise indicated.

\title{
Micro-cutting of single-crystal metal: Finite-element analysis of deformation and material removal
}

PLEASE CITE THE PUBLISHED VERSION

https://doi.org/10.1016/j.ijmecsci.2016.09.021

PUBLISHER

(C) Elsevier

VERSION

AM (Accepted Manuscript)

\section{PUBLISHER STATEMENT}

This work is made available according to the conditions of the Creative Commons Attribution-NonCommercialNoDerivatives 4.0 International (CC BY-NC-ND 4.0) licence. Full details of this licence are available at: https://creativecommons.org/licenses/by-nc-nd/4.0/

\section{LICENCE}

CC BY-NC-ND 4.0

\section{REPOSITORY RECORD}

Liu, Qiang, Anish Roy, Shoichi Tamura, Takashi Matsumura, and Vadim Silberschmidt. 2016. "Micro-cutting of Single-crystal Metal: Finite-element Analysis of Deformation and Material Removal". Loughborough University. https://hdl.handle.net/2134/23025. 


\title{
Micro-cutting of single-crystal metal: finite-element analysis of deformation and material removal
}

\author{
Qiang Liu ${ }^{1}$, Anish Roy ${ }^{*}$, Shoichi Tamura ${ }^{2}$, Takashi Matsumura ${ }^{2}$, Vadim V Silberschmidt ${ }^{1}$ \\ ${ }^{1}$ Wolfson School of Mechanical, Electrical and Manufacturing Engineering, Loughborough University, \\ Loughborough, LE11 3TU, The UK \\ ${ }^{2}$ Department of Mechanical Engineering, Tokyo Denki University, 2-2 Kanda-Nishiki-cho, Chiyoda-ku, Tokyo \\ 101-8457, Japan
}

\begin{abstract}
This paper presents analysis of mechanics in a micro-cutting process of a single-crystal metal - mechanisms of deformation and material removal related to an anisotropic crystallographic structure of a work-piece. A crystal-plasticity theory was implemented in a finite-element (FE) modelling scheme to consider inherently anisotropic deformation of a single-crystal metal at micro-scale. A new shear-strain-based criterion and several conventional strain-based criteria were employed to simulate the material removal process, and their effect on the anisotropy of cutting forces was studied. Subsequently, the micro-cutting process of single-crystal copper was predicted using FE modelling by combining the crystal-plasticity theory and the proposed criterion of material removal. The validity of the present FE modelling methodology was corroborated through a comprehensive comparison between FE simulations and experimental data in terms of cutting forces, chip morphology, deformation field, pile-up patterns and misorientation angle in the work-piece.
\end{abstract}

Keywords: micro-cutting, single crystal plasticity, finite-element modelling

\footnotetext{
${ }^{*}$ Corresponding author, E-mail address:A.Roy3@lboro.ac.uk
} 


\section{Introduction}

A trend of product miniaturisation has led to a growing demand for high-precision microscale machining techniques for manufacture of micromechanical systems [1-3]. In contrast to conventional macro-scale machining, a process zone in micromachining is usually limited to only a few grains of a metallic work-piece material. A component in the micro-scale exhibits a different mechanical response to that observed in its macro-scale counterpart $[4,5]$; consequently, its cutting response in the micro-scale also differs significantly. For example, cutting forces and chip morphology were found to depend on crystal orientation in several experimental studies on micromachining of single-crystal metals [6, 7]. To better understand the process of local deformation and material removal at a tool-work-piece interface in a micromachining process, a thorough analysis of cutting mechanics at grain level is required [7-9].

In recent years, the finite-element (FE) method has been widely used to model the machining process of materials, including analysis of chip morphology [10], temperature effects [11, 12] and ultrasonic vibration [13], influence of cutting conditions on structure of machining subsurface $[14,15]$ as well as optimisation of machining parameters [16, 17]. Similar research was also conducted in the field of micromachining $[18,19]$; for example, in the work of Jin and Altintas [20], a relationship between cutting forces, chip thickness and a tool-edge radius was identified through series of FE simulations of micro-milling. Thus, FE simulations could provide an in-depth understanding of underpinning micromechanics in the micromachining process that are difficult to quantify experimentally. Liu and Melkote [21] adopted FE simulations to demonstrate a size effect in metal micro-cutting, i.e. a nonlinear increase in specific cutting energy with a decrease in depth-of-cut. The simulation results indicated that strain-gradients can lead to a size effect. 
However, in these studies, anisotropy at a grain-level, induced by a crystallographic structure, was not considered. To overcome this drawback, a single-crystal plasticity (SCP) theory, incorporating the effects of crystal orientation and activated slip systems, was developed [22] to study inherently anisotropic deformation behaviour at a smallest practical length scale of metallic materials. The theory was used successfully to capture some of wellknown experimental observations in single crystals, including uniaxial experiments [23, 24] and nanoindentation studies $[25,26]$. Some efforts were also made to apply the SCP theory in modelling of micro-cutting processes. Studies by Abolfazl et al. [27] and Tajalli et al. [28] showed that chip formation and cutting forces in single-crystal copper depended on the initial crystal orientations in the work-piece with respect to a cutting direction. Moreover, the works by Demiral et al. [29] and Pal and Stucker [30], based on strain-gradient crystal-plasticity simulations, indicated that inhomogeneous plastic deformation could affect machinability of a work-piece. These studies lack comprehensive experimental validations. Recently, Lee et al. [31] adopted the SCP theory to analyse a variation of cutting forces and shear angles induced by crystallographic anisotropy. The model was able to predict the general trend of force variation; however, the magnitude of cutting forces was severely under-predicted for most directions when compared to experimental results.

Kim and Yoon [32] introduced several simplified isotropic damage models into the SCP theory, including those based on principal strain, equivalent plastic strain, maximum shear strain and strain energy, to describe the damage evolution of single-crystal metal. It was claimed that the maximum-shear-strain-based damage model provided the most accurate prediction when compared to experimental data. On a related note, since extreme shear deformation usually occurs at the interface of a cutting tool and a work-piece during machining, an alternative shear-strain-based criterion, which accounts for the accumulated shear strain over all the slip systems, was employed to model the material-removal process in 
micro-cutting by Demiral et al. [29]. Each modelling approach suffers from some shortcomings, and a comprehensive investigation with regard to the influences of different damage criteria on modelling of material removal in micro-cutting processes is lacking. The main primary goal of this paper is to elucidate mechanics of the micro-cutting process of single-crystal metal through the use of advanced FE modelling. Special attention is paid to the anisotropic effect of deformation and material removal at the scale of individual grains.

This paper is organized as follows: a theoretical framework of the SCP theory and its numerical implementation are summarized in Section 2, followed by a description of the suggested modelling procedure in Section 3. Mesh-sensitivity and a comparison of different material-removal modelling schemes are analysed in Section 4. Micro-cutting of singlecrystal copper using the proposed modelling approach is studied in the subsequent section. We conclude with some remarks in Section 6.

\section{Constitutive relations}

\subsection{Theory}

In this section, a classical crystal-plasticity theory adopted in this study is reviewed. A deformation gradient, $\mathbf{F}$, can be decomposed into its elastic and plastic parts:

$$
\mathbf{F}=\mathbf{F}_{\mathrm{e}} \mathbf{F}_{\mathbf{p}}
$$

where the subscripts 'e' and 'p' denote the elastic and plastic parameters, respectively. By applying the product rule of differentiation, one can obtain the rate of the total deformation gradient, $\dot{\mathbf{F}}$, as

$$
\dot{\mathbf{F}}=\dot{\mathbf{F}}_{\mathrm{e}} \mathbf{F}_{\mathbf{p}}+\mathbf{F}_{\mathrm{e}} \dot{\mathbf{F}}_{\mathbf{p}}
$$

Therefore, the velocity gradient, $\mathbf{L}$, can be introduced following its definition $\mathbf{L}=\dot{\mathbf{F}} \mathbf{F}^{-1}$ as

$$
\mathbf{L}=\dot{\mathbf{F}}_{\mathrm{e}} \mathbf{F}_{\mathrm{e}}^{-1}+\mathbf{F}_{\mathrm{e}}\left(\dot{\mathbf{F}}_{\mathrm{p}} \mathbf{F}_{\mathrm{p}}^{-1}\right) \mathbf{F}_{\mathrm{e}}^{-1}=\mathbf{L}_{\mathrm{e}}+\mathbf{L}_{\mathrm{p}}
$$


It is assumed that the plastic velocity gradient, $\mathbf{L}_{\mathbf{p}}$, is induced by shearing on each slip system in a crystal. Hence, $\mathbf{L}_{\mathbf{p}}$ is formulated as the sum of shear rates on all the slip systems, i.e.

$$
\mathbf{L}_{\mathbf{p}}=\sum_{\alpha=1}^{N} \dot{\gamma}^{(\alpha)} \mathbf{s}^{(\alpha)} \otimes \mathbf{m}^{(\alpha)}
$$

where $\dot{\gamma}^{(\alpha)}$ is the shear slip rate on the slip system $\alpha, N$ is the total number of slip systems, and unit vectors $\mathbf{s}^{(\alpha)}$ and $\mathbf{m}^{(\alpha)}$ define the slip direction and the normal to the slip plane in the deformed configuration, respectively. Furthermore, the velocity gradient can be expressed in terms of a symmetric rate of stretching, $\mathbf{D}$, and an antisymmetric rate of spin, $\mathbf{W}$ :

$$
\mathbf{L}=\mathbf{D}+\mathbf{W}=\left(\mathbf{D}_{\mathrm{e}}+\mathbf{W}_{\mathrm{e}}\right)+\left(\mathbf{D}_{\mathrm{p}}+\mathbf{W}_{\mathrm{p}}\right)
$$

Using Eqs. (3) and (4), it can be deduced

$$
\mathbf{D}_{\mathbf{e}}+\mathbf{W}_{\mathbf{e}}=\dot{\mathbf{F}}_{\mathbf{e}} \mathbf{F}_{\mathbf{e}}^{-\mathbf{1}}, \mathbf{D}_{\mathbf{p}}+\mathbf{W}_{\mathbf{p}}=\sum_{\alpha=1}^{N} \dot{\gamma}^{(\alpha)} \mathbf{s}^{(\alpha)} \otimes \mathbf{m}^{(\alpha)}
$$

Following the work of Huang [33], a constitutive law is expressed as the relationship between the elastic part of the symmetric rate of stretching, $\mathbf{D}_{\mathbf{e}}$, and the Jaumann rate of Cauchy stress, $\stackrel{\nabla}{\sigma}$, i.e.

$$
\stackrel{\nabla}{\sigma}+\sigma\left(I: D_{e}\right)=C:\left(D-D_{p}\right)
$$

where $\mathbf{I}$ is the second-order unit tensor, $\mathbf{C}$ is the fourth-order, possibly anisotropic, elastic stiffness tensor. The Jaumann stress rate is expressed as

$$
\stackrel{\nabla}{\sigma}=\dot{\sigma}-W_{e} \sigma+\sigma W_{e}
$$

On each slip system, the resolved shear stress, $\tau^{(\alpha)}$, is expressed by a Schmid law,

$$
\tau^{(\alpha)}=\operatorname{sym}\left(\mathbf{s}^{(\alpha)} \otimes \mathbf{m}^{(\alpha)}\right): \boldsymbol{\sigma} .
$$


The relationship between the shear rate, $\dot{\gamma}^{(\alpha)}$, and the resolved shear stress, $\tau^{(\alpha)}$, on the slip system $\alpha$ is expressed by a power law proposed by Hutchinson [34]:

$$
\dot{\gamma}^{(\alpha)}=\dot{\gamma}_{0}\left|\frac{\tau^{(\alpha)}}{g^{(\alpha)}}\right|^{n} \operatorname{sgn}\left(\tau^{(\alpha)}\right),
$$

where $\dot{\gamma}_{0}$ is the reference shear rate, $g^{(\alpha)}$ is the slip resistance and $n$ is the rate-sensitivity parameter. The evolution of $g^{(\alpha)}$ is given by

$$
\dot{\boldsymbol{g}}^{(\alpha)}=\sum_{\beta=1}^{N} h_{\alpha \beta}\left|\dot{\gamma}^{(\beta)}\right|
$$

where $h_{\alpha \beta}$ is the hardening modulus that can be calculated in the form modified from that proposed by Asaro [35],

$$
h_{\alpha \alpha}=\left(h_{0}-h_{s}\right) \operatorname{sech}^{2}\left[\frac{\left(h_{0}-h_{s}\right) \gamma}{\tau_{s}-\tau_{0}}\right]+h_{s}, h_{\alpha \beta}=q h_{\alpha \alpha}(\alpha \neq \beta), \gamma=\sum_{\alpha} \int_{0}^{t}\left|\dot{\gamma}^{(\alpha)}\right| d t .
$$

Here, $h_{0}$ and $h_{s}$ are the initial and saturated hardening moduli, respectively, $q$ is the latent hardening ratio, $\tau_{0}$ and $\tau_{S}$ are the shear stresses at the onset of yield and the saturation of hardening, respectively, and $\gamma$ is the accumulative shear strain over all the slip systems.

\subsection{Implementation in finite-element environment}

Implementation of the SCP theory in an implicit ABAQUS FE environment, by means of a user subroutine (UMAT), was introduced in the work of Huang [33], where a time integration scheme and a stress update algorithm were presented as

$$
\begin{gathered}
\dot{\gamma}^{(\alpha)} \Delta t=\Delta \gamma^{(\alpha)}=\Delta t\left[\left.(1-\theta) \dot{\gamma}^{(\alpha)}\right|_{t}+\left.\theta \dot{\gamma}^{(\alpha)}\right|_{t+\Delta t}\right], \\
\Delta \boldsymbol{\sigma}=\boldsymbol{\sigma} \Delta t .
\end{gathered}
$$

Here, $\Delta t$ is the time increment in the FE calculation; $\theta$ ranges from 0 to 1 , representing different time integration schemes (as an example, setting $\theta=0$ yields a simple Euler time 
integration scheme); the Jaumann stress rate, $\stackrel{\nabla}{\boldsymbol{\sigma}}$, was defined in Eq. (8). In this paper, the SCP theory is implemented employing a VUMAT subroutine in the explicit ABAQUS environment. The time integration scheme was identical to the one implemented in the UMAT; however, the stress update algorithm had to be modified due to the difference of the defined stress rate for ABAQUS/Standard and ABAQUS/Explicit formulations. The former employed the Jaumann stress rate, but the latter was based on the Green-Naghdi stress rate [36].

In contrast to the Jaumann stress rate defined in Eq. (8), the Green-Naghdi stress rate is defined as

$$
\stackrel{\Delta}{\sigma}=\dot{\sigma}-\Omega_{\mathrm{e}} \sigma+\sigma \Omega_{\mathrm{e}}
$$

Here, $\boldsymbol{\Omega}$ was found from a right polar decomposition of the total deformation gradient, $\mathbf{F}$, as

$$
\mathbf{\Omega}=\dot{\mathbf{R}} \cdot \mathbf{R}^{\mathrm{T}}, \quad \mathbf{F}=\mathbf{V R},
$$

where $\mathbf{R}$ and $\mathbf{V}$ are the right rotation and stretch tensors, respectively. To evaluate the stress update defined by the Green-Naghdi stress rate by using the Jaumann rate, one can use the Hughes-Winget algorithm [37], as

$$
\begin{gathered}
\left.\boldsymbol{\sigma}\right|_{t+\Delta t}=\left.\Delta \mathbf{R} \boldsymbol{\sigma}\right|_{t} \Delta \mathbf{R}^{\mathbf{T}}+\Delta \boldsymbol{\sigma}, \\
\Delta \mathbf{R}=\left[\mathbf{I}-\frac{1}{2}(\Delta \mathbf{W}-\Delta \mathbf{\Omega})\right]^{-1}\left[\mathbf{I}+\frac{1}{2}(\Delta \mathbf{W}-\Delta \mathbf{\Omega})\right], \\
\Delta \mathbf{W}=\mathbf{W} \Delta t, \Delta \mathbf{\Omega}=\mathbf{\Omega} \Delta t,
\end{gathered}
$$

where $\Delta \mathbf{R}$ is the relative spin increment tensor and $\mathbf{I}$ is the second-order unit tensor, $\Delta \boldsymbol{\sigma}$ is the stress increment obtained with the Jaumann stress rate (Eq. (14)). Another essential difference in ABAQUS/Explicit is that the stress and strain tensors are defined based on the spatial coordinate system (i.e. with respect to the local coordinate system rotating with the volume), in contrast to the material coordinate system (i.e. a fixed global coordinate system) 
used in ABAQUS/Standard. Therefore, during the conversion of UMAT to VUMAT, the stress update algorithm in VUMAT should be rewritten as

$$
\left.\boldsymbol{\sigma}\right|_{t+\Delta t}=\left.\Delta \mathbf{R} \boldsymbol{\sigma}\right|_{t} \Delta \mathbf{R}^{\mathbf{T}}+\mathbf{R} \Delta \boldsymbol{\sigma} \mathbf{R}^{\mathbf{T}}
$$

\section{Modelling procedure}

\subsection{Finite-element model}

Without loss of generality, single-crystal copper with a face-centred cubic (FCC) crystallographic structure was used in the study. A three-dimensional (3D) FE model was developed to simulate a micro-cutting process as shown in Fig. 1a to reflect experimental studies. The cutting tool had a wedge angle of $60^{\circ}$ and a clearance angle of $6.25^{\circ}$. For FCC single-crystal copper, slip was assumed to occur on the usual twelve $\{111\}<110>$ slip systems (see Table 1). In our simulations, the cutting tool was assumed to be rigid, and the contact condition between the cutting tool and the work-piece was assumed to be frictionless. The cutting direction was in the negative X direction (Fig. 1a), with a cutting velocity of 10 $\mathrm{mm} / \mathrm{min}$. The groove produced by micro-cutting is shown in Fig $1 \mathrm{~b}$, which is a result of two stages of micro-cutting. In Stage 1, a linearly increasing cutting depth (ranging from 0 to a target depth) was set for the cutting tool; while in Stage 2 a constant cutting depth (the target

depth) was retained. In our FE simulations, two different target depths were considered - 8 and $18 \mu \mathrm{m}$. To reduce a computational cost, the two stages of micro-cutting were modelled using two FE models. In the first model, the length, height and width of the work-piece were $340 \mu \mathrm{m}, 200 \mu \mathrm{m}$ and $120 \mu \mathrm{m}$, respectively. In the second model, the respective magnitudes were $240 \mu \mathrm{m}, 200 \mu \mathrm{m}$ and $120 \mu \mathrm{m}$. 

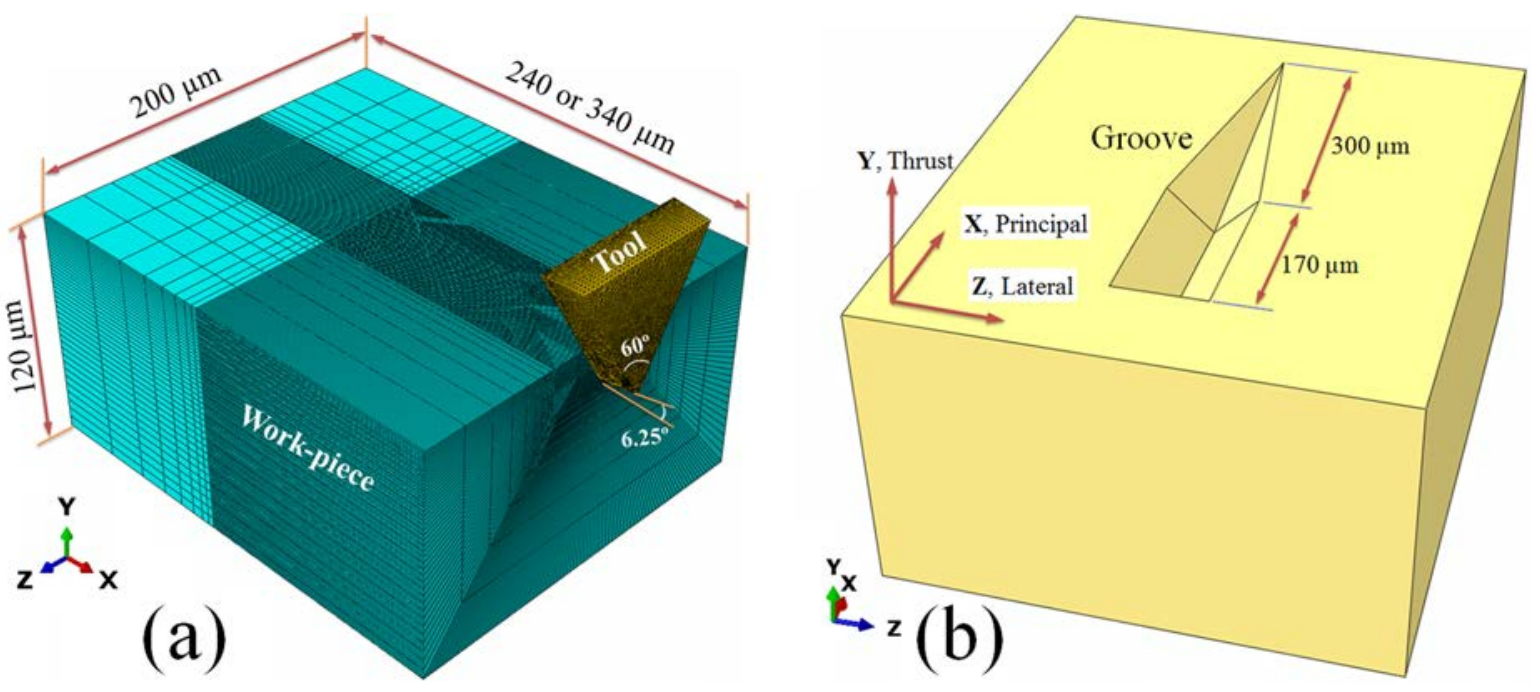

Fig. 1 (a) Finite-element model for simulation of micro-cutting and (b) groove geometry

Table 1 Twelve slip systems in FCC single-crystal copper

\begin{tabular}{ccccccccccccc}
\hline & 1 & 2 & 3 & 4 & 5 & 6 & 7 & 8 & 9 & 10 & 11 & 12 \\
\hline $\mathbf{s}^{(\alpha)}$ & $0 \overline{1} 1$ & $10 \overline{1}$ & $\overline{1} 10$ & 101 & 110 & $0 \overline{1} 1$ & 011 & 110 & $10 \overline{1}$ & $\overline{1} 10$ & 101 & 011 \\
$\mathbf{m}^{(\alpha)}$ & 111 & 111 & 111 & $\overline{1} 11$ & $\overline{1} 11$ & $\overline{1} 11$ & $1 \overline{1} 1$ & $1 \overline{1} 1$ & $1 \overline{1} 1$ & $11 \overline{1}$ & $11 \overline{1}$ & $11 \overline{1}$ \\
\hline
\end{tabular}

The work-piece was meshed using eight-node brick elements with reduced integration (C3D8R) available in ABAQUS. To improve accuracy, a finer local mesh was used in regions near the cutting zone with a height of $27 \mu \mathrm{m}$. In this study, the [110] crystal orientation corresponds to a normal of the top surface of the work-piece. Three orientations were chosen as cutting directions: [1-10], and the other two rotated by angles of $45^{\circ}$ (i.e. [1$1 \sqrt{2}]$ ) and $90^{\circ}$ (i.e. [001]) with respect to it. The cutting forces were defined as follows: a force along the cutting direction (X direction) is called the principal force, and those along the $\mathrm{Y}$ and $\mathrm{Z}$ directions are the thrust and lateral forces, respectively (Fig. 1b).

\subsection{Modelling of material removal}

To our knowledge, three main modelling techniques are usually employed to simulate material removal: element deletion [29, 38], arbitrary Lagrangian-Eulerian adaptive 
remeshing (ALE) [18, 20, 39] and smooth particle hydrodynamics (SPH) [27, 40, 41]. Our studies indicated that the three modelling techniques produce almost identical results for the cutting forces, however, the element deletion technique was the most computationally efficient [42]. Consequently, the modelling technique of element deletion was employed in this paper.

To incorporate element deletion or material removal in an FE simulation, a damage criterion was required [18]. In this paper, five different damage criteria are considered for the modelling of material removal. Three of those were based on a simplified damage model; the respective criteria were based on principal strain, equivalent plastic strain and maximum shear strain. Next, an approach based on the shear strain accumulated over all slip systems was considered as per the work of Demiral et al. [29]. Finally, a new shear strain-based criterion was proposed to account for anisotropy in the material-removal process, as follows:

$$
\begin{aligned}
& \max \left(\gamma-\gamma_{c r}, \quad \gamma_{s l, \min }-\gamma_{s l, c r}\right) \geq 0, \\
& \gamma_{s l, \min }=\min \left(\gamma^{(\alpha)}\right), \alpha=1,2 \cdots N,
\end{aligned}
$$

where $\gamma_{s l, c r}$ and $\gamma_{c r}$ are the critical values of shear strain on a single slip system and the accumulated shear strain on all the slip systems, respectively. That is, damage in a single crystal is considered based on two scenarios of partial and full activation of slip systems. In other words, both shear on individual slip systems as well as the overall slip due to all slip systems are monitored. If either the critical value for an individual slip system $\left(\gamma_{s l, c r}\right)$ or the accumulated slip $\left(\gamma_{c r}\right)$ is attained, the element is removed. In our study, the values of $\gamma_{c r}$ and $\gamma_{s l, c r}$ was 6.0 and 0.068 , respectively; these parameters were chosen based on initial calibration tests. In a nominal sense, these values imply that failure in a single-crystal copper occurs easier for the full activation of slip systems than for that of a partial one. 


\subsection{Calibration of material parameters}

Experimental data for single-crystal copper under compression reported by Takeuchi [43] were employed to calibrate parameters of the work-piece material. As shown in Fig. 2, numerical results obtained after calibration show an excellent match with the experimental data for both [100] and [111] crystal orientations. The calibrated model parameters are listed in Table 2, and were used to simulate the micro-cutting process.

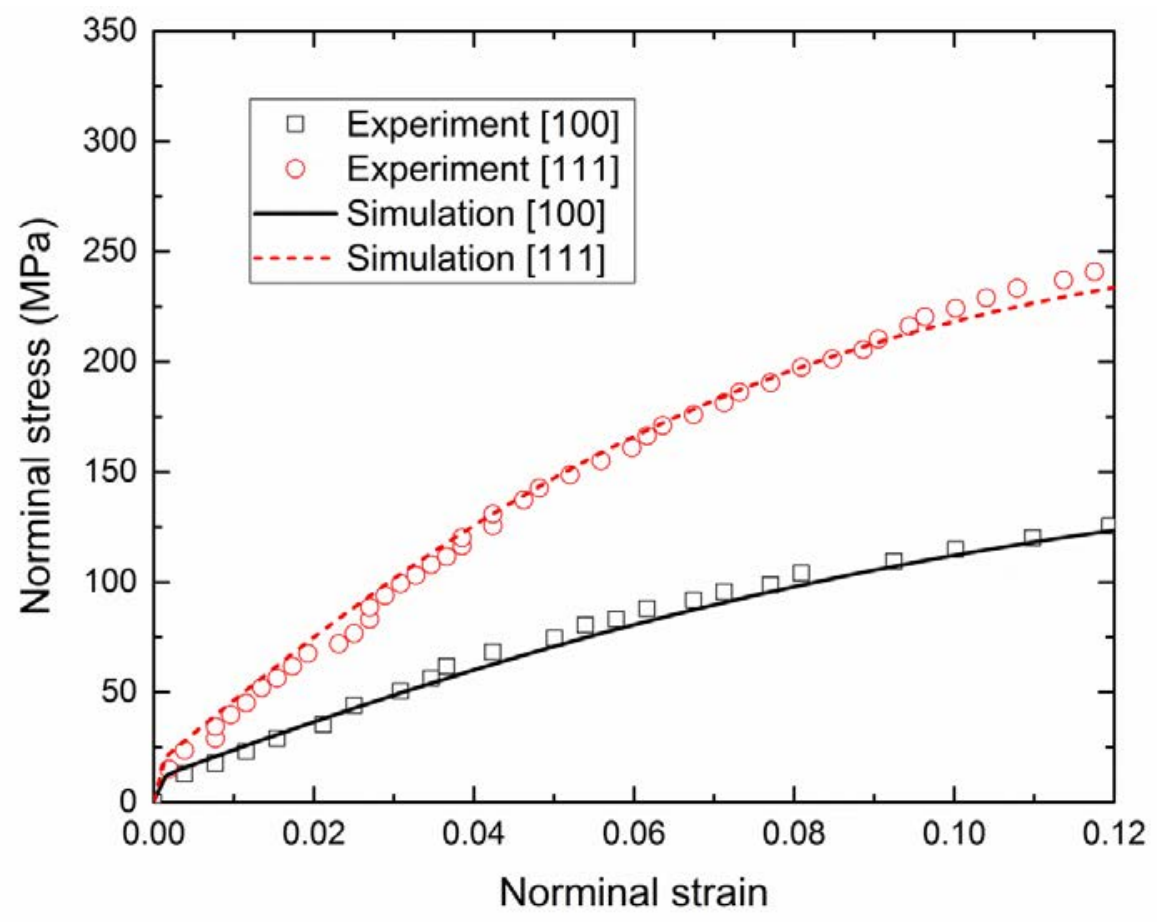

Fig. 2 Comparison of experimental and numerical stress-strain behaviour under compression for single-crystal copper

Table 2 Material parameters of single-crystal copper

\begin{tabular}{cllc}
\hline Parameter & Definition & Value & Unit \\
\hline$\dot{\gamma}_{0}$ & Reference shear rate & 0.001 & $\mathrm{~s}^{-1}$ \\
$n$ & Rate-sensitivity parameter & 50 & - \\
\hline
\end{tabular}




\begin{tabular}{clcc}
\hline$\tau_{0}$ & Initial slip resistance & 4.0 & $\mathrm{MPa}$ \\
$\tau_{s}$ & Saturated slip resistance & 52 & $\mathrm{MPa}$ \\
$h_{0}$ & Initial hardening modulus & 180 & $\mathrm{MPa}$ \\
$h_{s}$ & Saturated hardening modulus & 24 & $\mathrm{MPa}$ \\
$q$ & Latent hardening ratio & 1.2 & - \\
\hline
\end{tabular}

\section{Analysis}

\subsection{Mesh-sensitivity analysis}

For mesh-sensitivity studies, the Stage 2 of micro-cutting was considered, with a fixed cutting depth of $18 \mu \mathrm{m}$. Without loss of generality, micro-cutting along [1-10] (or $0^{\circ}$ direction) was considered. Here a parameter, $N$, was defined providing a number of elements along the height of the cutting tool (Y direction as per Fig 1 (a)), to represent the mesh density used. The influence of mesh on the calculated cutting forces is shown in Fig. 3 for the microcutting along $0^{\circ}$ direction; both the principal and thrust forces are presented. For all the cases, the cutting forces initially increased with the engagement of the cutting tool, approaching a nominally constant level with full tool engagement in the work-piece. As shown in Fig. 3, the cutting forces decreased with increasing $N$. The effect of the mesh became less significant when $N$ exceeds 25, and the difference between the cases of $N=30$ and $N=35$ was negligible. To give an estimate, the total number of elements used for $N=30$ corresponded to $\sim 1 \times 10^{6}$ brick elements. For the rest if the study, the mesh corresponding to $N=30$ was chosen as an acceptable balance between computational accuracy and efficiency. 


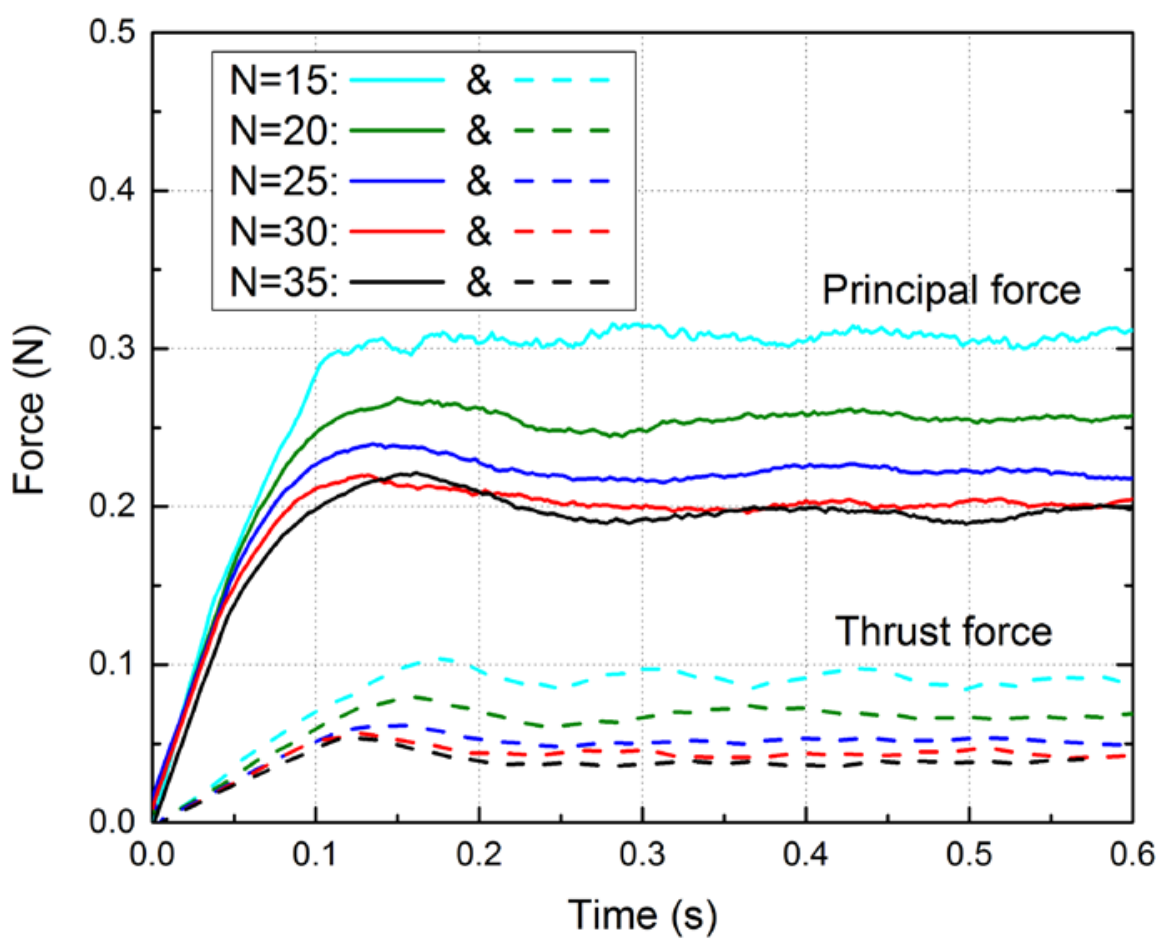

Fig. 3 Influences of mesh number on predicted cutting forces

\subsection{Comparison of different material-removal modelling schemes}

Here, the influence of different damage criteria on predicted anisotropy of cutting forces with respect to chosen cutting directions was studied. The intention was to attain a good correlation with regard to cutting-force magnitudes (in contrast to prior studies [29]). As before, only Stage 2 of micro-cutting with a depth of $18 \mu \mathrm{m}$ was considered. The average cutting forces were calculated from the nominally steady cutting region (i.e. after full engagement of the cutting tool). To better present the anisotropic effect predicted by different material-removal modelling schemes, the normalized cutting forces, $f$, was defined as

$$
f=\frac{F}{F_{p, 0}} .
$$

Here $F$ is the true cutting force, and $F_{p, 0}$ is the principal force in the $0^{\circ}$ direction. 


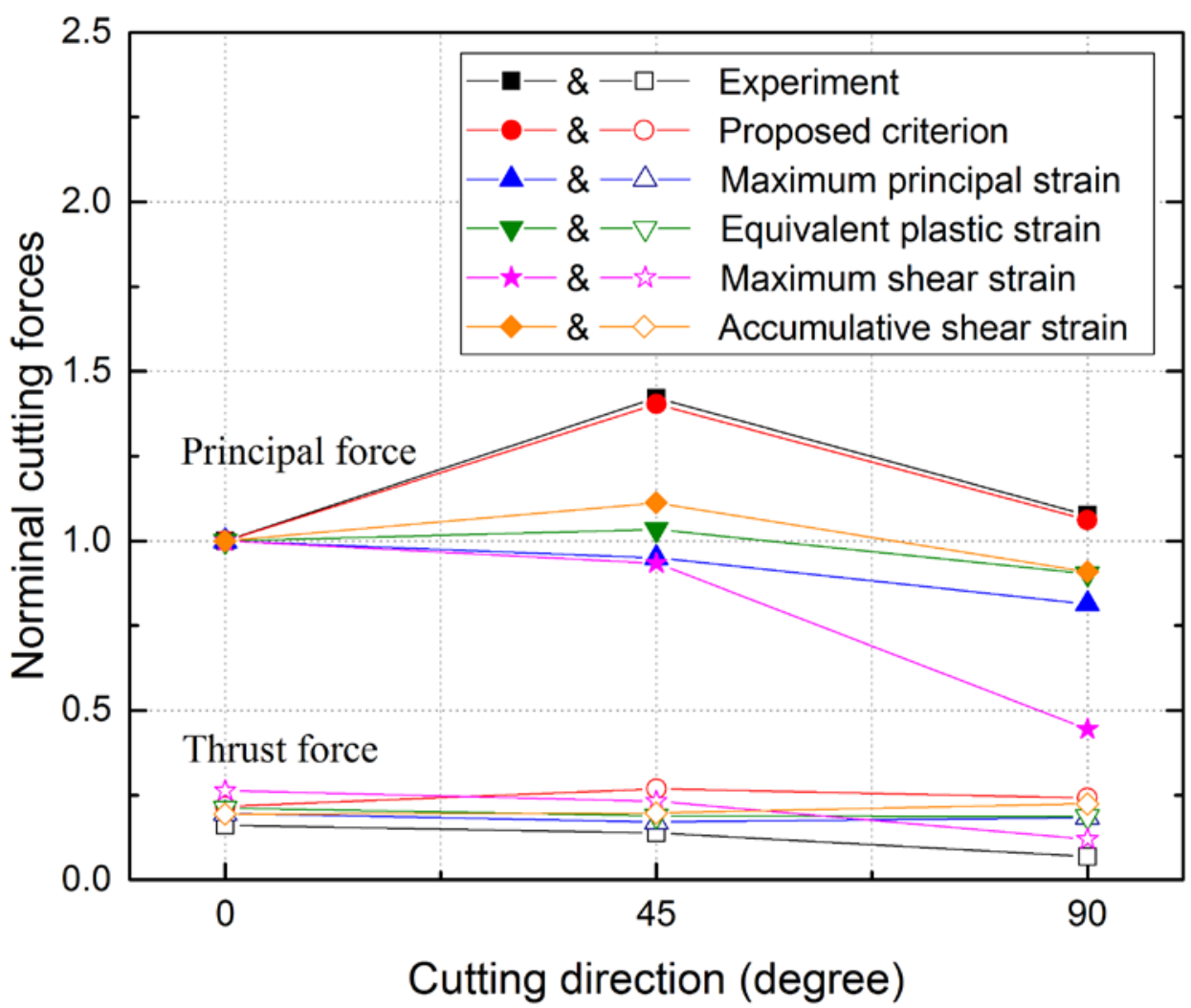

Fig. 4 Comparison of different criteria for material-removal modelling

The variations of normalized average cutting forces with the cutting directions, obtained with different material-removal models, are shown in Fig. 4. The obtained results are compared to experimental data performed by our partners at Tokyo Denki University, Japan. The effect of anisotropy is more pronounced in measurements of principal force in comparison to those for thrust force. It is clear that the choice of material-removal modelling has a noticeable influence of the predicted cutting forces for different cutting directions. The proposed criterion (Eq. (21)) captures anisotropy of the principal force more accurately when compared to other criteria. For example, the experimental data show that the principal force in $45^{\circ}$ direction is about $40 \%$ higher than that in $0^{\circ}$ direction; however, the criteria of equivalent plastic strain and accumulative shear strain only predicted $4 \%$ and $11 \%$ increases, respectively, while the criteria of maximum principal strain and shear strain even resulted in a decrease of $5 \%$ and $7 \%$, respectively. This indicates that the simplified isotropic damage 
models were not sufficient to describe the failure of single-crystal metals, which are inherently anisotropic.

Thus, it can be concluded that the material-removal model is an important factor to predict cutting forces in addition to deformation behaviour as described by the SCP theory.

\section{Results and discussion}

In this section, the micro-cutting process of single-crystal copper (i.e. Stages 1 and 2) was predicted by combining the SCP theory and our proposed material-removal modelling. To verify the presented FE modelling, comprehensive experimental validations were carried out in terms of cutting forces, chip morphology, deformation field and misorientation angle of the single-grain Cu work-piece [44].

\subsection{Cutting forces}

The variation of cutting forces with time during a full micro-cutting process is shown in Figs. 5 and 6, corresponding to the cutting depth of 18 and $8 \mu \mathrm{m}$, respectively. The simulation results and experimental data of $0^{\circ}$ and $45^{\circ}$ cutting directions are reported here for each cutting depth. These cutting force-time curves cover two stages: Stage 1 with an increasing depth and Stage 2 with a constant depth of cut. In Stage 1, both principal and thrust forces grew with time due to the continuing increase in the cutting depth. In Stage 2, the cutting forces approached a nominally constant value. Here, the cutting process in Stage 2 was carried out for 1 second. As the two stages in the micro-cutting were simulated using two different FE runs, an apparent discontinuity was observed on the cutting force-time curves (due to concatenation of two curves). The experimental curves also show a clear discontinuity at the point of transition from Stage 1 to Stage 2; this is due to the nature of the experiment, in which, at the completion of Stage 1, the tool movement was stopped before the start of Stage 2. As shown in both Figs. 5 and 6, the simulation results correlate well with the experimental data for the principal forces (with the exception of the discontinuous region 
between the stages). A significant dependence of the principal force on crystal orientation was observed both in the experiments and the simulations. In Stage 2, the principal force for the $45^{\circ}$ direction was about $40 \%$ higher than that for the $0^{\circ}$ direction for the cutting depth of $18 \mu \mathrm{m}$ (Fig. 5), and about 30\% higher for $8 \mu \mathrm{m}$ (Fig. 6). This anisotropy in the principal force was accurately captured in the FE simulations, thus validating the suggested criterion of material removal. Predictions for the thrust-force were comparatively less accurate for the studies cases; a possible reason for this could be their relatively low magnitude. The thrust forces showed a lower dependence on the cutting direction both in the simulation results and the experimental data for the normal to the work-piece surface fixed at the [110] crystal orientation.
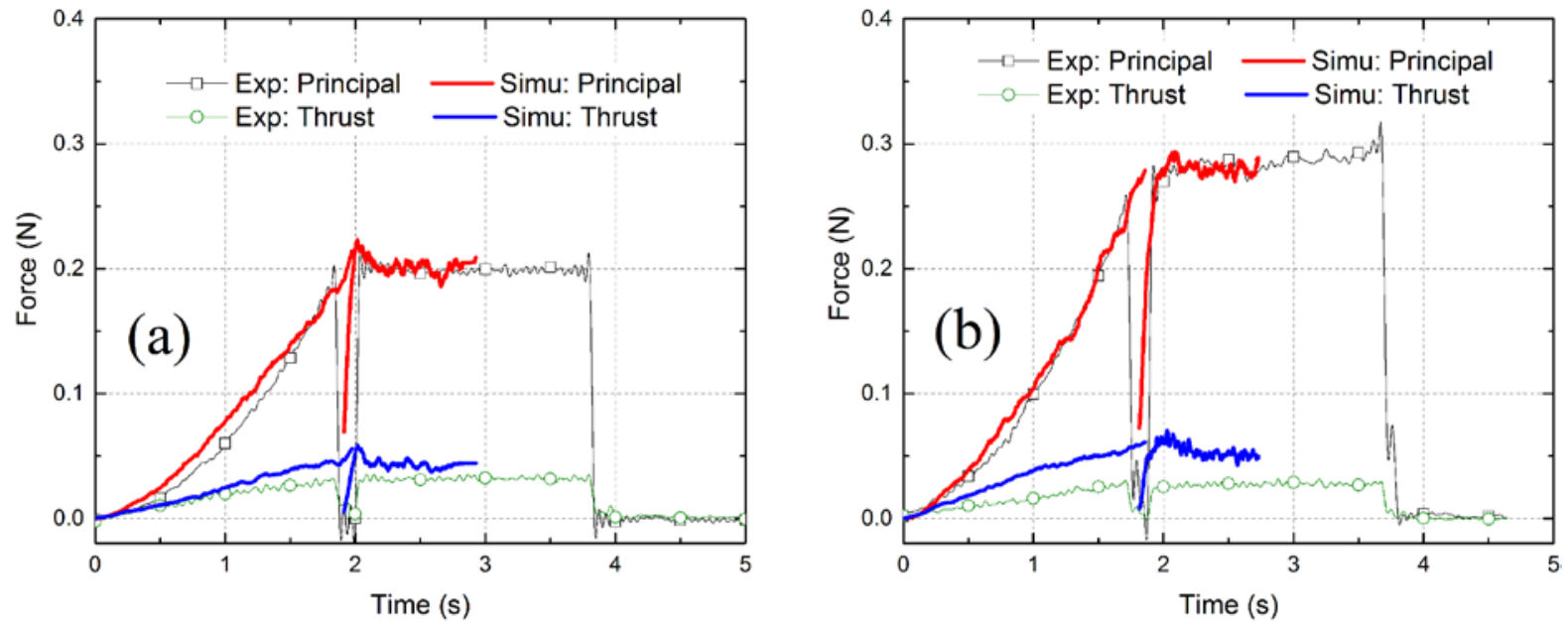

Fig. 5 Comparison of cutting forces from experimental data and FE simulations in microcutting of single-crystal copper with depth of $18 \mu \mathrm{m}$ for $0^{\circ}$ (a) and $45^{\circ}$ (b) directions 

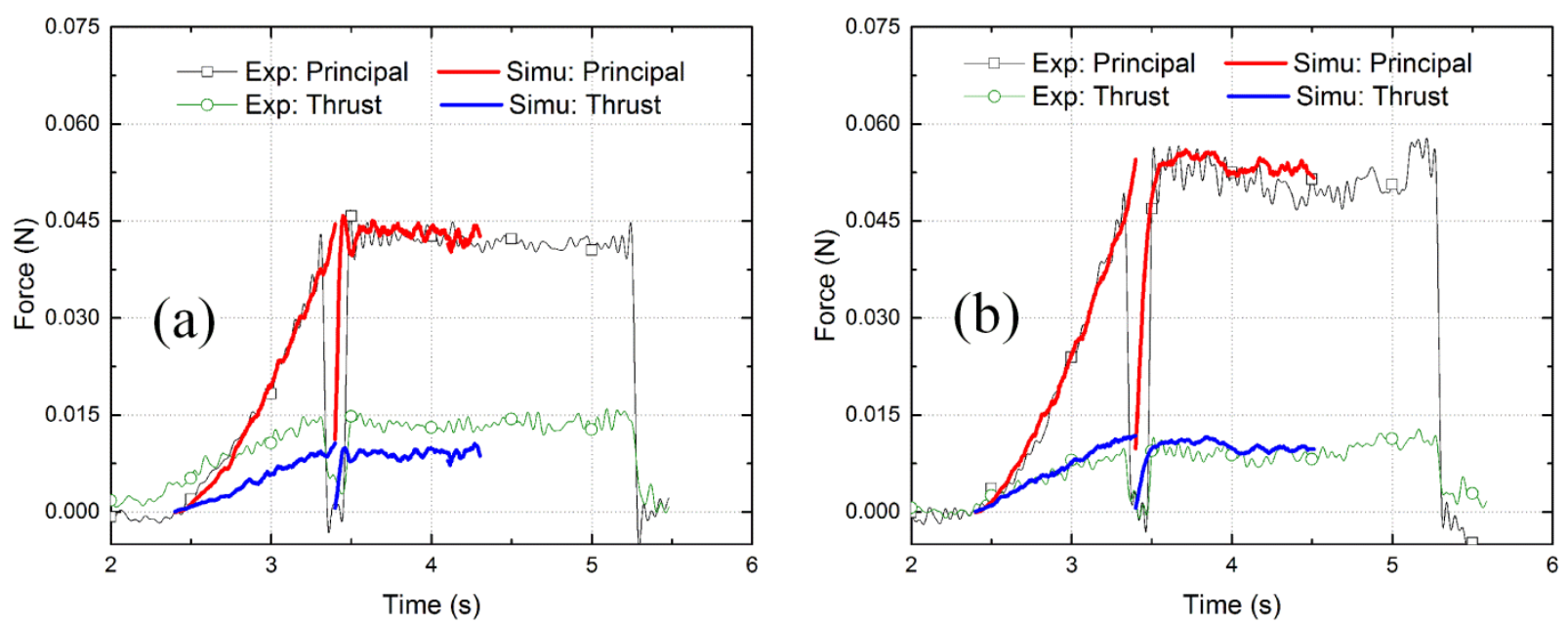

Fig. 6 Comparison of cutting forces from experimental data and FE simulations in microcutting of single-crystal copper with depth of $8 \mu \mathrm{m}$ for $0^{\circ}$ (a) and $45^{\circ}$ (b) directions

\subsection{Chip morphology}

An important aspect in FE simulations of metal machining is their capability of capturing chip morphology. For the rest of the study, the case with the final cutting depth of $18 \mu \mathrm{m}$ is considered. The chip morphology obtained with our FE simulations and in the experiment is compared in Fig. 7. When cutting was performed along the $0^{\circ}$ direction (i.e. [1-10] orientation), slip systems activated in the FCC crystallographic structure were symmetrical with respect to it. Therefore, in the FE simulation, the chip separated from the work-piece symmetrically. The stress field was also symmetric with regard to the cutting plane (Fig. 7a). The simulated chip morphology was verified by the experimental results shown in the in Fig. 7b. In contrast, micro-cutting along the $45^{\circ}$ direction yielded an asymmetrical stress field and chip formation (Figs. 7c and d) as the cutting direction did not coincide with main axes of symmetry of the FCC structure of the work-piece material. 


\section{$0^{\circ}$ direction}
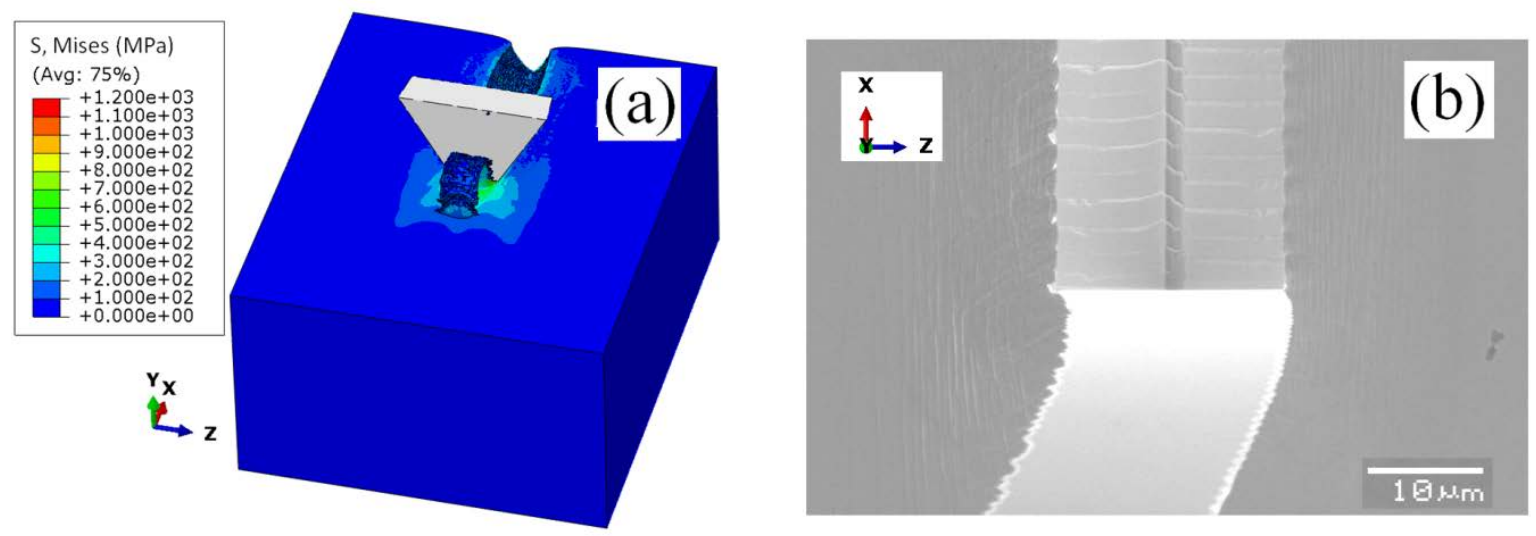

$45^{\circ}$ direction
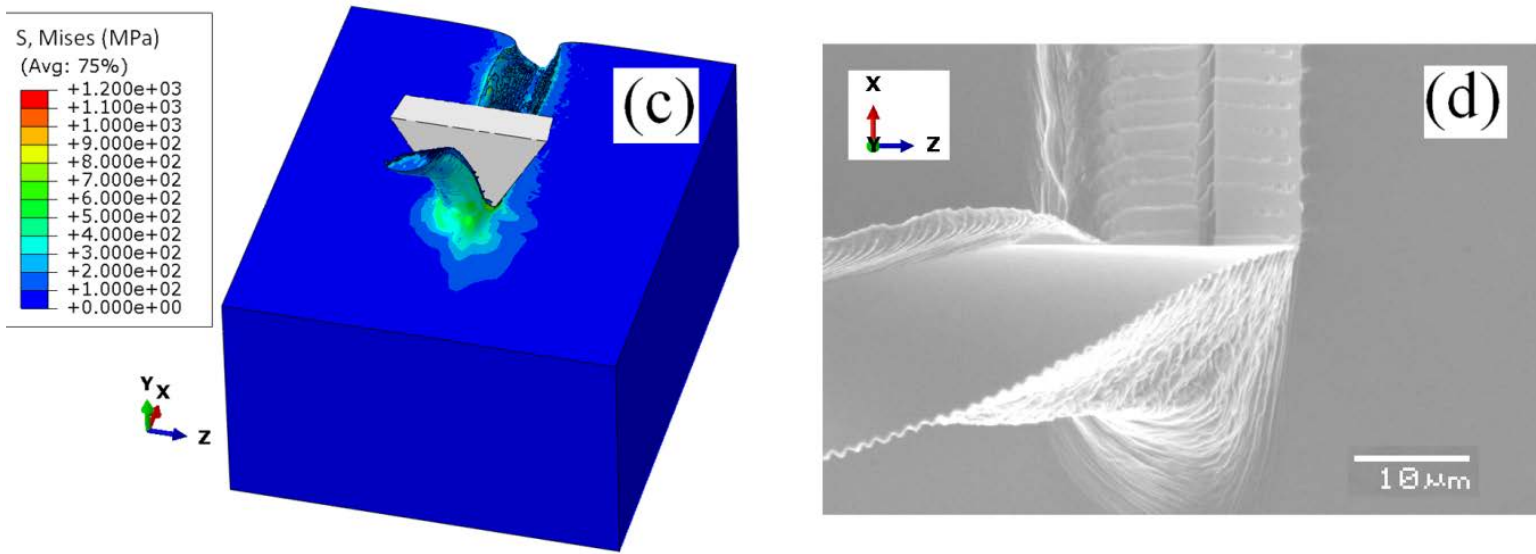

Fig. 7 Comparison of chip morphology from FE simulations and experiments in microcutting of single-crystal copper: (a) simulation in $0^{\circ}$ direction; (b) experiment in $0^{\circ}$ direction; (c) simulation in $45^{\circ}$ direction; (d) experiment in $45^{\circ}$ direction

\subsection{Deformation of work-piece}

The deformation process in the work-piece caused by the machining process is discussed next. A distribution of displacement normal to the work-piece's surface is shown in Fig. 8 for both $0^{\circ}$ and $45^{\circ}$ directions (here, the chip was removed for clarity). Again, symmetrical and asymmetrical deformation fields in the work-piece were observed for the micro-cutting in the $0^{\circ}$ and $45^{\circ}$ directions, respectively. Ahead of the cutting process zone, higher deformation was observed for directions at about $\pm 45^{\circ}$ with respect to the cutting direction for microcutting in the $0^{\circ}$ direction; however, larger deformations were found to the right of the cutting 
direction (-Z direction in Fig 8(d)) for micro-cutting in the $45^{\circ}$ direction. Consequently, the pile-up height to the right of the groove was larger than that to the left in the FE simulation for micro-cutting in the $45^{\circ}$ direction. The surface profile of the deformed work-piece was measured in the experiments (Figs. 8(b) and (d)), which was compared to that obtained from simulations at the locations indicated in Figs. 8 (a) and (c) (Path AB, CD).
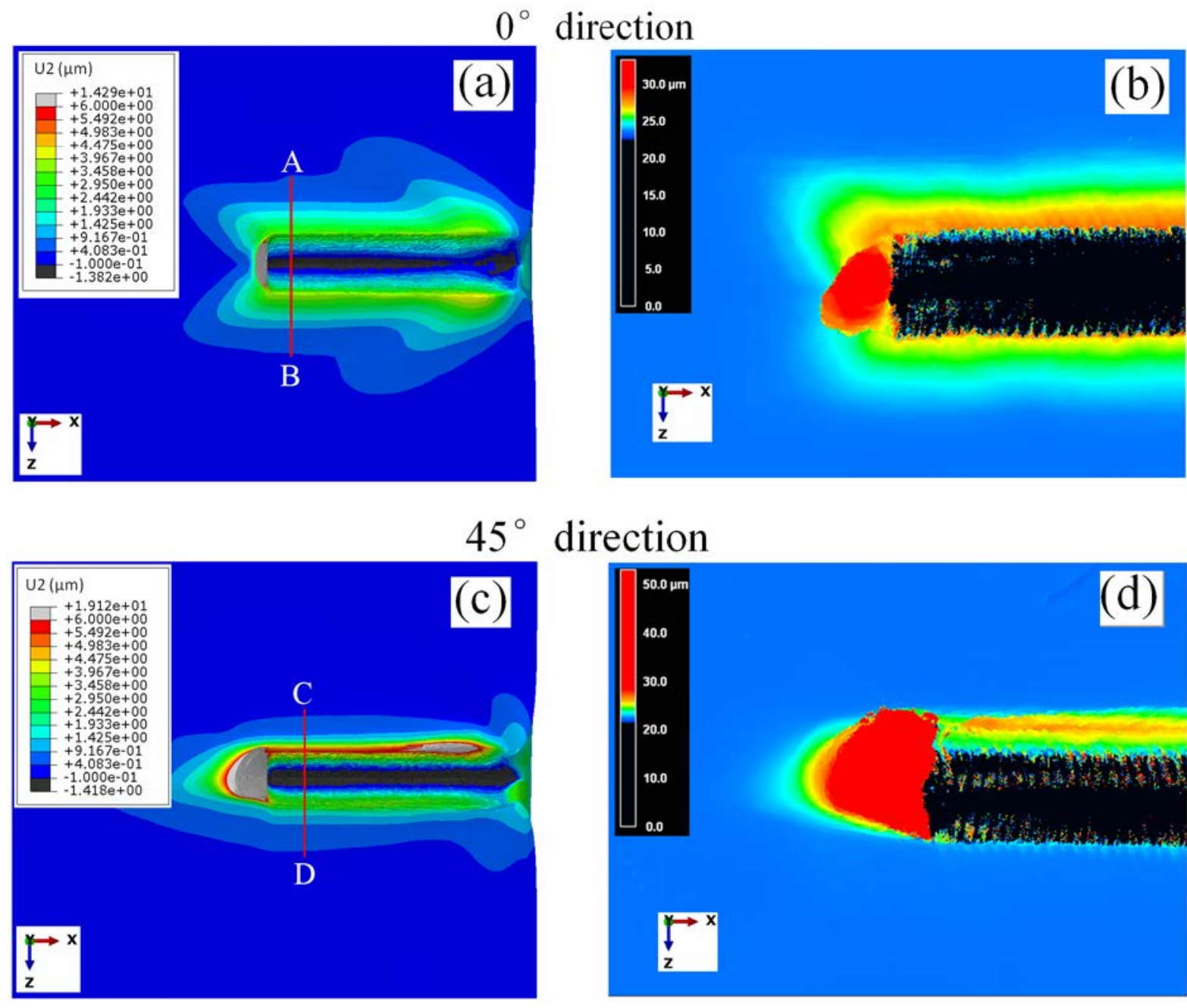

Fig. 8 Comparison of displacement fields in work-piece from FE simulation and experimental data on micro-cutting of single-crystal copper: (a) simulation in $0^{\circ}$ direction; (b) experiment in $0^{\circ}$ direction; (c) simulation in $45^{\circ}$ direction; (d) experiment in $45^{\circ}$ direction 

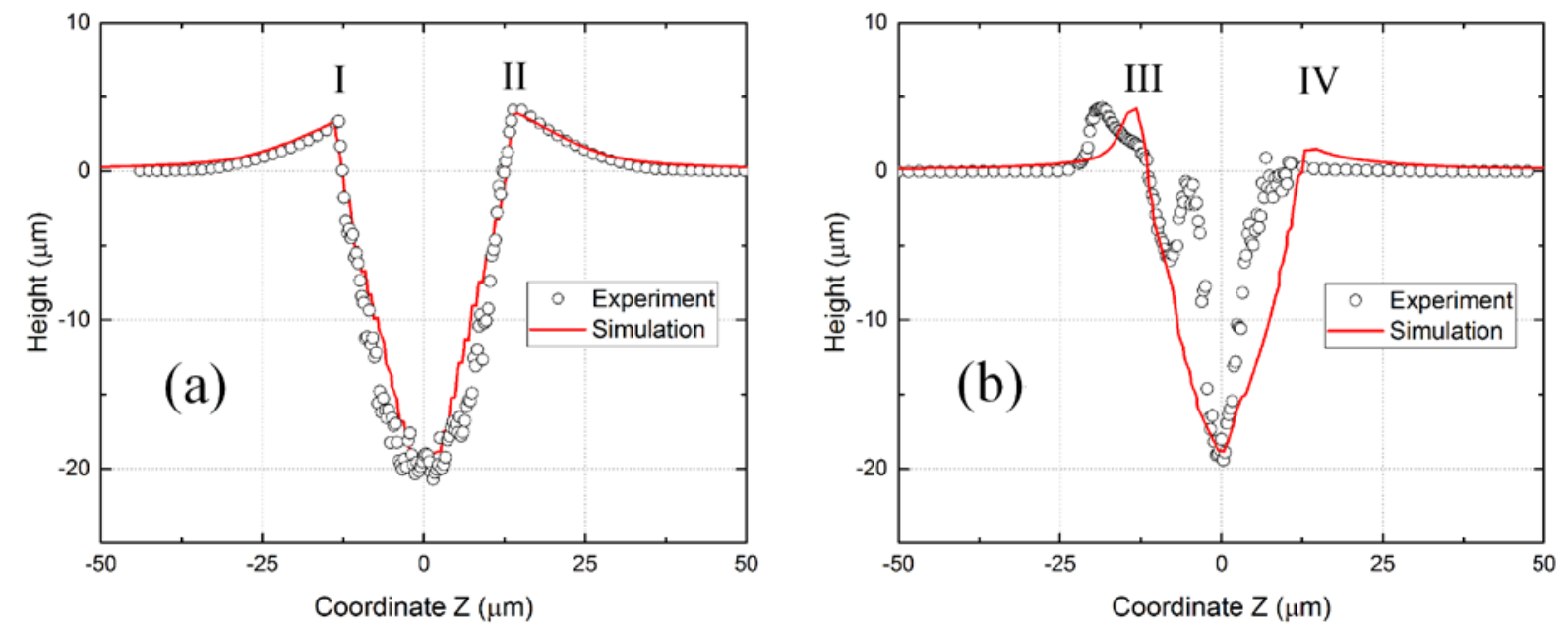

Fig. 9 Pile-up profiles across groove obtained with FE simulation and experiment: (a) $0^{\circ}$ direction (Line AB, Fig. 8a) and (b) $45^{\circ}$ direction (Line CD, Fig. 8c)
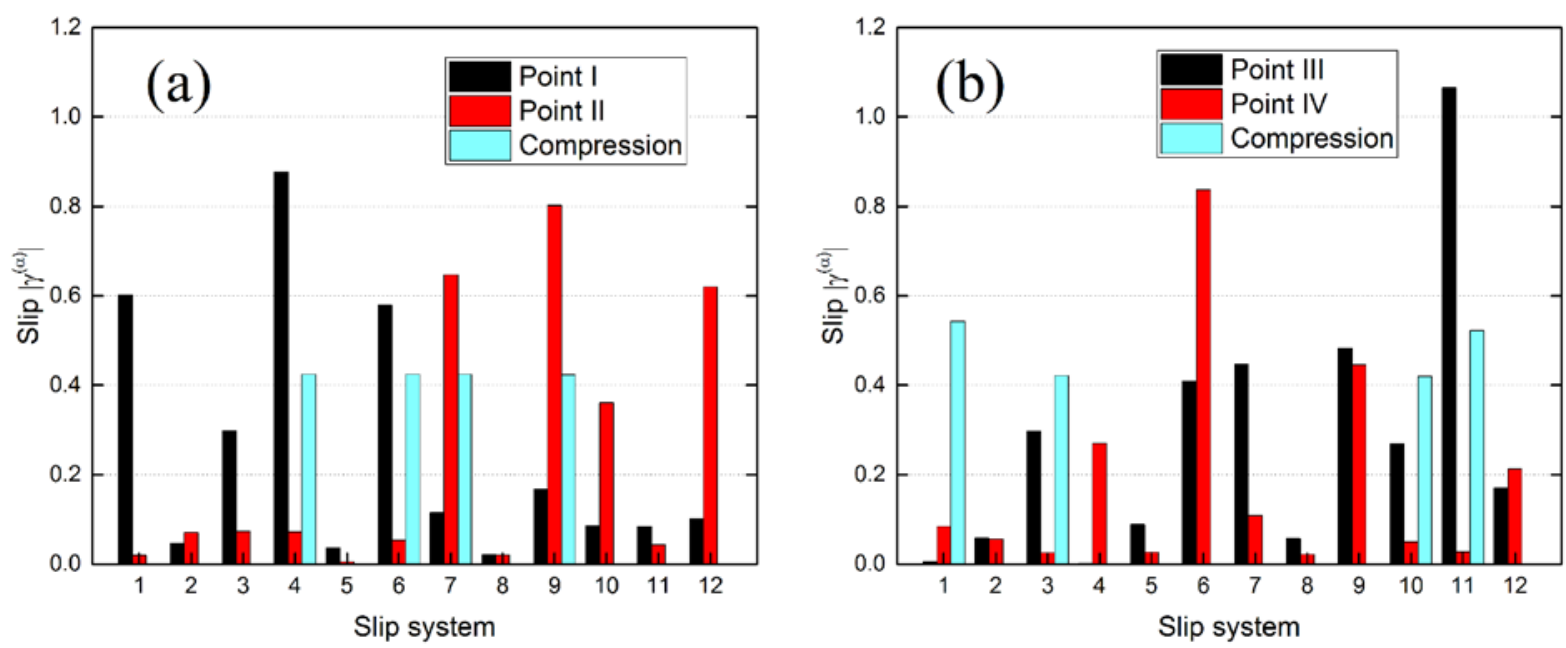

Fig. 10 Slip-system activation at peak pile-up height: $0^{\circ}$ (a) and $45^{\circ}$ (b) directions

The pile-up profiles perpendicular to the groove (paths $A B$ and $C D$ in Fig. 8) are shown in Fig. 9 for two respective directions. It is clear that the residual imprint post machining depends on the cutting direction. An excellent agreement between the FE simulation results and the experimental data was obtained for the residual groove imprint for cutting in the $0^{\circ}$ direction. In experiments, a minor asymmetry was observed with regard to the pile-up height on either side of the groove. This is due to the difficulty in ensuring a perfect spatial orientation of the cutting process due to inherent errors and precision of the system (see Fig. $7 \mathrm{~b}$ - the chip curls away from the central cutting direction). For results of cutting in the $45^{\circ}$ 
direction there were some differences when compared to the experimental data. Here, we would like to point out that the experimental data obtained with a laser microscope was noisy, and the results presented are based on averaging the data from several scans. The FE simulation provided a reasonable prediction of the pile-up height across the groove (Fig. 9b).

Magnitudes of slip on each slip system at four locations (I through IV in Fig. 9) corresponding to peak heights, are represented in Fig. 10. The slip systems 1 and 12 were arranged mirror-symmetrically relative to the [001] plane that is parallel to the $0^{\circ}$ cutting direction; similarly, for slip systems 2 and 11, 3 and 10, and so forth (see Table 1). For microcutting in the $0^{\circ}$ direction, at points I and II there were four dominant slip systems activated symmetrically relative to the cutting direction, which explains the symmetrical pile-up profile observed in Fig. 9(a). The total accumulative slip at point I was almost identical to that at point II. In contrast, for cutting in the $45^{\circ}$ direction, the slip-system activation at point III is different from that at point IV. There is a higher accumulative slip at point III in comparison to point IV, which explains the higher pile-up height observed at point III in Fig. 9(b).

The activation of slip systems in the cutting process is complex. For a pure compression test performed in the material in the $0^{\circ}$ and $45^{\circ}$ directions, the slip-system activation would be completely different to that observed from the cutting process. In Fig. 10, the slip-system activation corresponding to a case of pure compression (with $50 \%$ strain) is provided for comparison, demonstrating that different slip systems were activated with varying magnitudes. Thus, simplified deformation studies cannot capture the anisotropy effect in the micro-cutting of crystalline materials.

In summary, the simulation results agreed well with the experimental data for the pile-up height and general features of the post-machining deformation imprint. 


\subsection{Misorientation angle of work-piece}

To characterize the variation of crystallographic orientation of the work-piece after the micro-cutting process, the concept of misorientation angle [45] was invoked here, which is expressed as

$$
\theta=\min \left|\cos ^{-1}\left\{\frac{\operatorname{tr}\left(\mathbf{g}_{A} \mathbf{g}_{B}^{-1} \mathbf{O}-1\right)}{2}\right\}\right|,
$$

where $\theta$ is the misorientation angle, $\mathbf{g}_{A}$ and $\mathbf{g}_{B}$ is the orientation matrix at chosen spatial locations A and B, respectively, and $\mathbf{O}$ is the crystal symmetry operator. There are a total of 24 identical rotation operations in the case of FCC symmetry [45]. In this paper, the undeformed crystallographic structure was considered as the reference configuration for calculation of the misorientation angle. The variation of the misorientation angle along the path P-Q (which is perpendicular to the groove) is shown in Fig. 11(a) for the $0^{\circ}$ direction. As deformation of the work-piece was nearly symmetrical for micro-cutting along the $0^{\circ}$ direction (Fig. 9), only the misorientation angles on one side of the cut groove was assessed as shown in Fig. 10(a). A good agreement between the FE simulations and experimental data is apparent. The variation of crystallographic orientation was close to $20^{\circ}$ for this cutting direction.

Using the developed model, the variation of the misorientation angles for cutting in the $45^{\circ}$ direction was predicted (Fig. 11b). Here, path (R-S) across the groove was chosen because of the asymmetry of cutting in this direction. As expected, the misorientation angle was asymmetrical along the path R-S, with larger misorientation angles corresponding to the surface region with a higher pile-up height (Fig. 11b). The magnitude of misorientation angle is also relatively larger than that for $0^{\circ}$ direction. Experiments will be conducted in the near future to verify the effectiveness of the predictive capability of the developed model. 

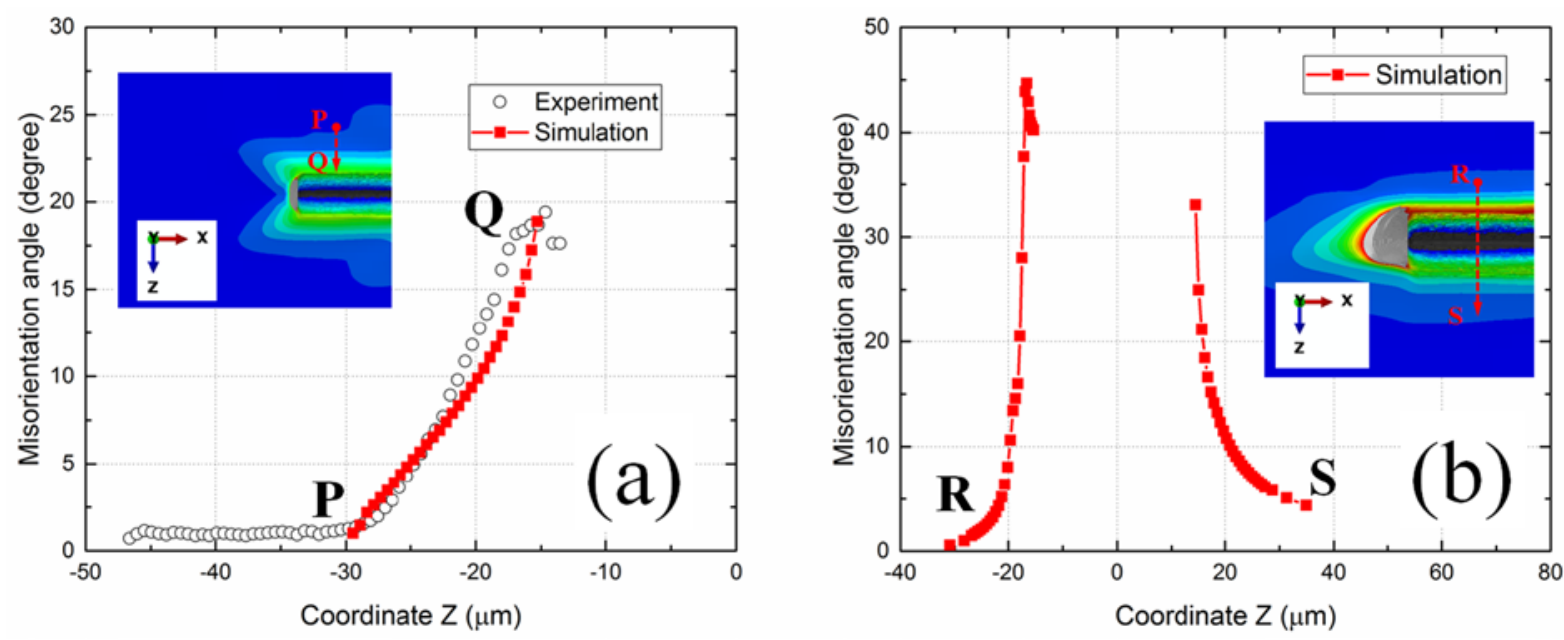

Fig. 11 Misorientation angle across groove: (a) $0^{\circ}$ direction, comparing FE simulation and experiment; (b) $45^{\circ}$ direction, prediction based on FE simulation.

\section{Concluding Remarks}

A FE modelling approach for the micro-cutting process of single-crystal metals was presented, incorporating a new shear-strain-based criterion, accounting for the partial and full activation of slip systems. The model is shown to capture the inherent anisotropy of the damage process in single crystals, which in turn has a significant effect on prediction of anisotropy of cutting forces. Crucially, the study indicates that a suitable chip separation criterion is critical for accurate application of crystal-plasticity theory in micro-cutting of single-crystal metal.

The numerical model is compared against experimental studies. The model is capable of capturing some of essential characteristics of the machining process, namely, cutting forces, chip morphology, pile-up profiles as well as misorientation angle for the machined workpiece surface. The model was used to predict misorientation angles in other cutting directions, and can be employed to predict machining-induced deformations and stresses across any cutting plane and direction. 


\section{Acknowledgement}

Funding from the Engineering and Physical Sciences Research Council (UK) through grant EP/K028316/1 and Department of Science and Technology (India), project MAST, is gratefully acknowledged.

\section{Reference}

[1] U. Engel, R. Eckstein, Microforming-from basic research to its realization, Journal of Materials Processing Technology, 125 (2002) 35-44.

[2] S. Zhang, S. To, S. Wang, Z. Zhu, A review of surface roughness generation in ultraprecision machining, International Journal of Machine Tools and Manufacture, 91 (2015) 7695.

[3] S. Zhang, S. To, G. Zhang, Z. Zhu, A review of machine-tool vibration and its influence upon surface generation in ultra-precision machining, International Journal of Machine Tools and Manufacture, 91 (2015) 34-42.

[4] J.R. Greer, J.T.M. De Hosson, Plasticity in small-sized metallic systems: Intrinsic versus extrinsic size effect, Progress in Materials Science, 56 (2011) 654-724.

[5] O. Kraft, P.A. Gruber, R. Mönig, D. Weygand, Plasticity in confined dimensions, Annual Review of Materials Research, 40 (2010) 293-317.

[6] W. Lee, S. To, C. Cheung, Effect of crystallographic orientation in diamond turning of copper single crystals, Scripta Materialia, 42 (2000) 937-945.

[7] A. Mian, N. Driver, P. Mativenga, Identification of factors that dominate size effect in micro-machining, International Journal of Machine Tools and Manufacture, 51 (2011) 383394.

[8] B. Shi, H. Attia, Current status and future direction in the numerical modeling and simulation of machining processes: a critical literature review, Machining Science and Technology, 14 (2010) 149-188.

[9] J. Chae, S. Park, T. Freiheit, Investigation of micro-cutting operations, International Journal of Machine Tools and Manufacture, 46 (2006) 313-332.

[10] F. Ducobu, E. Rivière-Lorphèvre, E. Filippi, Material constitutive model and chip separation criterion influence on the modeling of Ti6Al4V machining with experimental validation in strictly orthogonal cutting condition, International Journal of Mechanical Sciences, (2016).

[11] S. Buchkremer, B. Wu, D. Lung, S. Münstermann, F. Klocke, W. Bleck, FE-simulation of machining processes with a new material model, Journal of Materials Processing Technology, 214 (2014) 599-611.

[12] V. Babitsky, A. Mitrofanov, V. Silberschmidt, Ultrasonically assisted turning of aviation materials: simulations and experimental study, Ultrasonics, 42 (2004) 81-86.

[13] A. Mitrofanov, V. Babitsky, V. Silberschmidt, Finite element analysis of ultrasonically assisted turning of Inconel 718, Journal of Materials Processing Technology, 153 (2004) 233239.

[14] F. Jafarian, M.I. Ciaran, D. Umbrello, P. Arrazola, L. Filice, H. Amirabadi, Finite element simulation of machining Inconel 718 alloy including microstructure changes, International Journal of Mechanical Sciences, 88 (2014) 110-121. 
[15] Y.M. Arısoy, C. Guo, B. Kaftanoğlu, T. Özel, Investigations on Microstructural Changes in Machining of Inconel 100 alloy using Face Turning Experiments and 3D Finite Element Simulations, International Journal of Mechanical Sciences, (2016).

[16] S. Elhami, M. Razfar, M. Farahnakian, Analytical, numerical and experimental study of cutting force during thermally enhanced ultrasonic assisted milling of hardened AISI 4140, International Journal of Mechanical Sciences, 103 (2015) 158-171.

[17] J. Díaz-Álvarez, J. Cantero, H. Miguélez, X. Soldani, Numerical analysis of thermomechanical phenomena influencing tool wear in finishing turning of Inconel 718, International Journal of Mechanical Sciences, 82 (2014) 161-169.

[18] D. Parle, R.K. Singh, S.S. Joshi, G. Ravikumar, Modeling of microcrack formation in orthogonal machining, International Journal of Machine Tools and Manufacture, 80 (2014) 18-29.

[19] W. Zong, Z. Cao, C. He, C. Xue, Theoretical modelling and FE simulation on the oblique diamond turning of ZnS crystal, International Journal of Machine Tools and Manufacture, 100 (2016) 55-71.

[20] X. Jin, Y. Altintas, Prediction of micro-milling forces with finite element method, Journal of Materials Processing Technology, 212 (2012) 542-552.

[21] K. Liu, S.N. Melkote, Finite element analysis of the influence of tool edge radius on size effect in orthogonal micro-cutting process, International Journal of Mechanical Sciences, 49 (2007) 650-660.

[22] F. Roters, P. Eisenlohr, L. Hantcherli, D. Tjahjanto, T. Bieler, D. Raabe, Overview of constitutive laws, kinematics, homogenization and multiscale methods in crystal plasticity finite-element modeling: Theory, experiments, applications, Acta Materialia, 58 (2010) 11521211.

[23] A.S. Khan, J. Liu, J.W. Yoon, R. Nambori, Strain rate effect of high purity aluminum single crystals: Experiments and simulations, International Journal of Plasticity, 67 (2015) 39-52.

[24] M. Lee, H. Lim, B. Adams, J. Hirth, R. Wagoner, A dislocation density-based single crystal constitutive equation, International Journal of Plasticity, 26 (2010) 925-938.

[25] W. Lee, Y. Chen, Simulation of micro-indentation hardness of FCC single crystals by mechanism-based strain gradient crystal plasticity, International Journal of Plasticity, 26 (2010) 1527-1540.

[26] M. Demiral, A. Roy, T. El Sayed, V.V. Silberschmidt, Influence of strain gradients on lattice rotation in nano-indentation experiments: A numerical study, Materials Science and Engineering: A, 608 (2014) 73-81.

[27] S.A. Zahedi, M. Demiral, A. Roy, V.V. Silberschmidt, FE/SPH modelling of orthogonal micro-machining of fcc single crystal, Computational Materials Science, 78 (2013) 104-109.

[28] S. Tajalli, M. Movahhedy, J. Akbari, Simulation of orthogonal micro-cutting of FCC materials based on rate-dependent crystal plasticity finite element model, Computational Materials Science, 86 (2014) 79-87.

[29] M. Demiral, A. Roy, T. El Sayed, V.V. Silberschmidt, Numerical modelling of micromachining of fcc single crystal: Influence of strain gradients, Computational Materials Science, 94 (2014) 273-278.

[30] D. Pal, B. Stucker, A study of subgrain formation in Al 3003 H-18 foils undergoing ultrasonic additive manufacturing using a dislocation density based crystal plasticity finite element framework, Journal of Applied Physics, 113 (2013) 203517.

[31] W. Lee, H. Wang, C. Chan, S. To, Finite element modelling of shear angle and cutting force variation induced by material anisotropy in ultra-precision diamond turning, International Journal of Machine Tools and Manufacture, 75 (2013) 82-86. 
[32] J.-B. Kim, J.W. Yoon, Necking behavior of AA 6022-T4 based on the crystal plasticity and damage models, International Journal of Plasticity, 73 (2015) 3-23.

[33] Y. Huang, A User-material Subroutine Incroporating Single Crystal Plasticity in the ABAQUS Finite Element Program, Harvard Univ., 1991.

[34] J. Hutchinson, Bounds and self-consistent estimates for creep of polycrystalline materials, Proceedings of the Royal Society of London. A. Mathematical and Physical Sciences, 348 (1976) 101-127.

[35] R.J. Asaro, Crystal plasticity, Journal of Applied Mechanics, 50 (1983) 921-934.

[36] A.U.s. Manual, Version 6.12, Karlsson \& Sorensen, Hibbitt Inc, (2012).

[37] T.J. Hughes, J. Winget, Finite rotation effects in numerical integration of rate constitutive equations arising in large-deformation analysis, International Journal for Numerical Methods in Engineering, 15 (1980) 1862-1867.

[38] Y.M. Arısoy, T. Özel, Prediction of machining induced microstructure in Ti-6Al-4V alloy using 3-D FE-based simulations: Effects of tool micro-geometry, coating and cutting conditions, Journal of Materials Processing Technology, 220 (2015) 1-26.

[39] S. Amini, H. Soleimanimehr, M. Nategh, A. Abudollah, M. Sadeghi, FEM analysis of ultrasonic-vibration-assisted turning and the vibratory tool, Journal of Materials Processing Technology, 201 (2008) 43-47.

[40] S.A. Zahedi, A. Roy, V.V. Silberschmidt, Modelling of vibration assisted machining fcc single crystal, Procedia CIRP, 31 (2015) 393-398.

[41] H. Zhang, X. Dong, Physically based crystal plasticity FEM including geometrically necessary dislocations: numerical implementation and applications in micro-forming, Computational Materials Science, 110 (2015) 308-320.

[42] Q. Liu, S. Dodla, A. Roy, V.V. Silberschmidt, Crystal-plasticity simulation of micromachining of single-crystal metal: methodology and analysis, in: K. Naumenko, M. Aßmus (Eds.) Advanced Methods of Continuum Mechanics for Materials and Structures, Springer-Verlag, 2016.

[43] T. Takeuchi, Work hardening of copper single crystals with multiple glide orientations, Transactions of the Japan Institute of Metals, 16 (1975) 629-640.

[44] S. Tamura, Q. Liu, S. Dodla, A. Roy, V.V. Silberschmidt, T. Matsumura, The paper title: Micro cutting of mono crystal copper, (In preparation).

[45] O. Engler, V. Randle, Introduction to texture analysis: macrotexture, microtexture, and orientation mapping, CRC press, 2009. 